\title{
What are the ideal screw lengths in volar locking plate fixation for distal radius fractures?
}

\author{
Kilian $\mathrm{M}^{1}$, Simkovic $\mathrm{P}^{1}$, Zamborsky $\mathrm{R}^{2}$, Skoda $\mathrm{A}^{3}$, Labas $\mathrm{P}^{3}$ \\ 2nd Orthopedic and Traumatology Department, University Hospital Saint Cyril and Metod \\ and Comenius University Bratislava, Slovakia. skoda.alexander@gmail.com
}

\begin{abstract}
PURPOSE: This study aimed to specify the optimal lengths of the distal locking screws (in a female population undergoing distal radius fracture fixation with a volar locking plate) to avoid damaging the dorsal extensor tendon compartments while preserving stability.

METHODS: Twenty-five female adult patients underwent volar locking plate fixation with four $2.4 \mathrm{~mm}$ locking screws inserted distally. Our modified dorsal tangential fluoroscopic view (DTV) was taken perioperatively followed by postoperative CT scans to compare the accuracy in determining the distal screw lengths.

RESULTS: Our modified DTV was $88 \%, 84 \%, 88 \%$, and $76 \%$ sensitive in detecting screw lengths in the first, second, third, and fourth distal plate holes, respectively. According to the CT scans, none of the screws were over-penetrated in the third dorsal compartment, over-penetration was found in the second and fourth dorsal compartment. The most-accurate screw lengths in the four most distal plate holes in female distal radius fracture are $14,20,20$, and $20 \mathrm{~mm}$ from the radial to the ulnar aspect.

CONCLUSION: In dorsal cortex comminution, when perioperative measuring is imprecise, inserting the mostsuitable distal locking screw for problematic hole and then applying our modified DTV seems to be a simpler and safer option (Tab. 3, Fig. 4, Ref. 33). Text in PDF www.elis.sk.

KEY WORDS: Dönicke view, dorsal tangential view, dorsal horizon view, skyline view.
\end{abstract}

\section{Introduction}

Fractures of the distal radius are frequent acute injuries, and their incidence is increasing $(1,2)$. Females are three times more affected than males (1-3). The most-popular treatment option of unstable distal radius fracture is volar locking plate fixation because of the lower rate of hardware-related complication in comparison to dorsal plating (4). Dorsal plating can harm extensor tendons because of their proximity to the bone surface, whereas with volar plating irritations of the flexor tendons are minimal if the plate is placed correctly and covered by the pronator quadratus muscle. However, hardware contact to extensor tendons could also occur in volar plating if improper screw lengths are used, penetrating the dorsal compartment and causing problems with the extensor tendons (irritation or damage) (4-7). The dorsal tangential view (DTV) has been described as a sensitive projection for checking distal screw lengths and their penetration through the dorsal cortex (DC) of the

12nd Orthopedic and Traumatology Department, University Hospital Saint Cyril and Metod and Comenius University Bratislava, Slovakia, ${ }^{2}$ Department of Orthopedics, Faculty of Medicine, Comenius University, Children's University Hospital, Bratislava, Slovakia, and ${ }^{3} 1$ st Clinic of Surgery, Faculty of Medicine, University Hospital Stare Mesto and Comenius University Bratislava, Slovakia

Address for correspondence: A. Skoda, MD, MPH, MBA, 1st Clinic of Surgery, Faculty of Medicine, University Hospital Stare Mesto and Comenius University Bratislava, Mickiewiczova 13, SK-813 69 Bratislava, Slovakia.

Phone: +421.2.57290333, Fax: +421.2.57290300 distal radius (8). According to some authors, such penetrations may be prevented by inserting screws that are $2-4 \mathrm{~mm}$ shorter than the measured length $(9,10)$. However, two issues exist. First, measuring the distance between the plate and the DC is usually quite problematic or even impossible when there is a substantial comminution, thereby making it difficult to calculate the final length. Second, reducing the screw length in shear-type injuries may lead to an inadequate dorsal ulnar fragment support and the carpus may become unstable $(5,6,11-14)$. The present study aimed to compare perioperative skyline views, and postoperative computed tomography (CT) scans in unstable distal radius fractures in female adults and to specify the ideal screw lengths (not too short, not too long) in three defined distal radius dorsal compartments in volar plating.

\section{Methods}

Between January 2015 and September 2017, we assessed 100 distal screws in 25 female adult patients (mean age $56 \mathrm{y}$; range 28-74 y) undergoing surgery because of an unstable and displaced distal radius fracture and who agreed to participate in the study. We excluded fractures that were pathological, open, or in which the affected wrist had concomitant and previous injuries or surgeries. In total, 12 right and 13 left distal radius fractures were treated by open reduction and internal fixation with a volar locking plate (VA-LCP Two-Column Distal Radius Plates 2.4, volar, six head holes, DePuySynthes, Switzerland). According to the AO classification system, there were 15 type 23-A fractures, two type 23-B, and eight type 23-C. The surgeries were performed by four orthopedic traumatolo- 

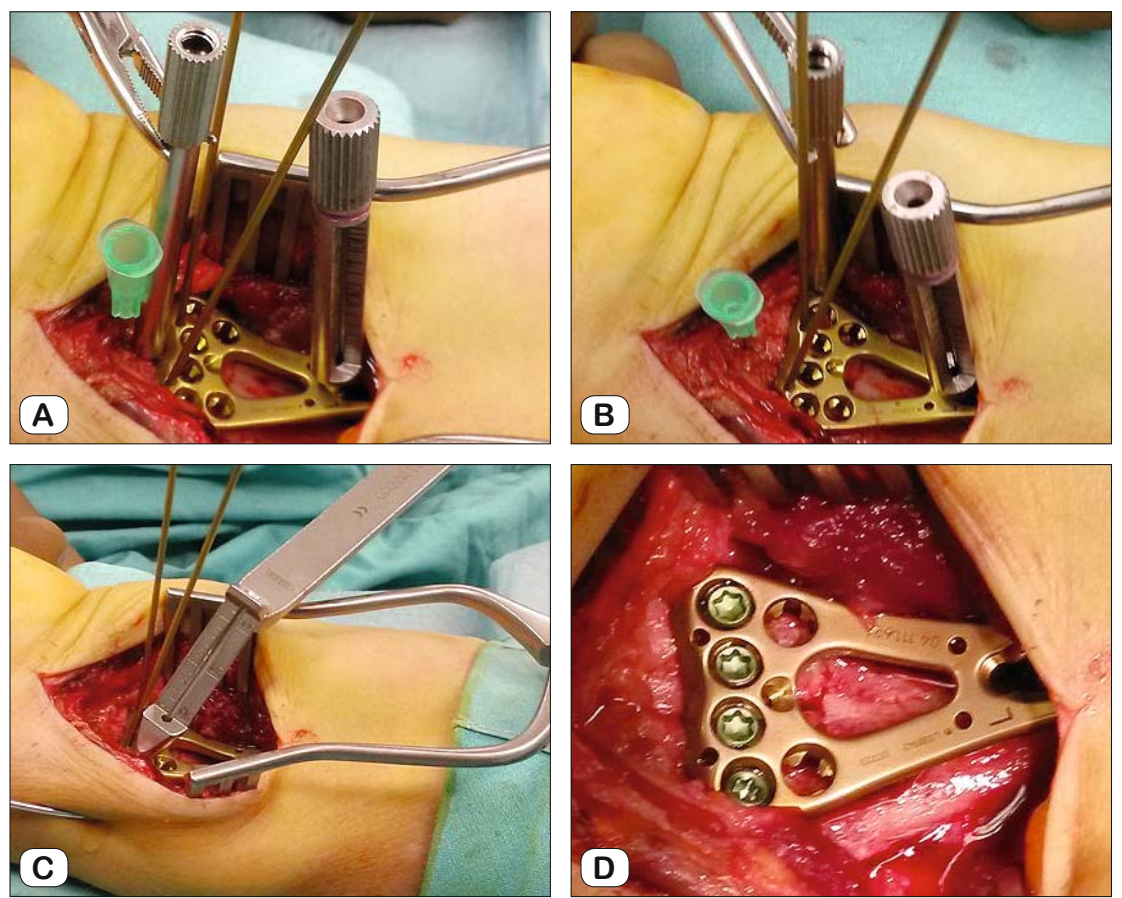

Fig. 1. Plate positioning was determined by placing a needle in the radio-carpal, another in the distal radioulnar joint, and attaching a drill sleeve measuring $5 \mathrm{~mm}$ in diameter (A, B). Only distal row screws $(C, D)$ were inserted from the radial to the ulnar aspect (holes 1-4).

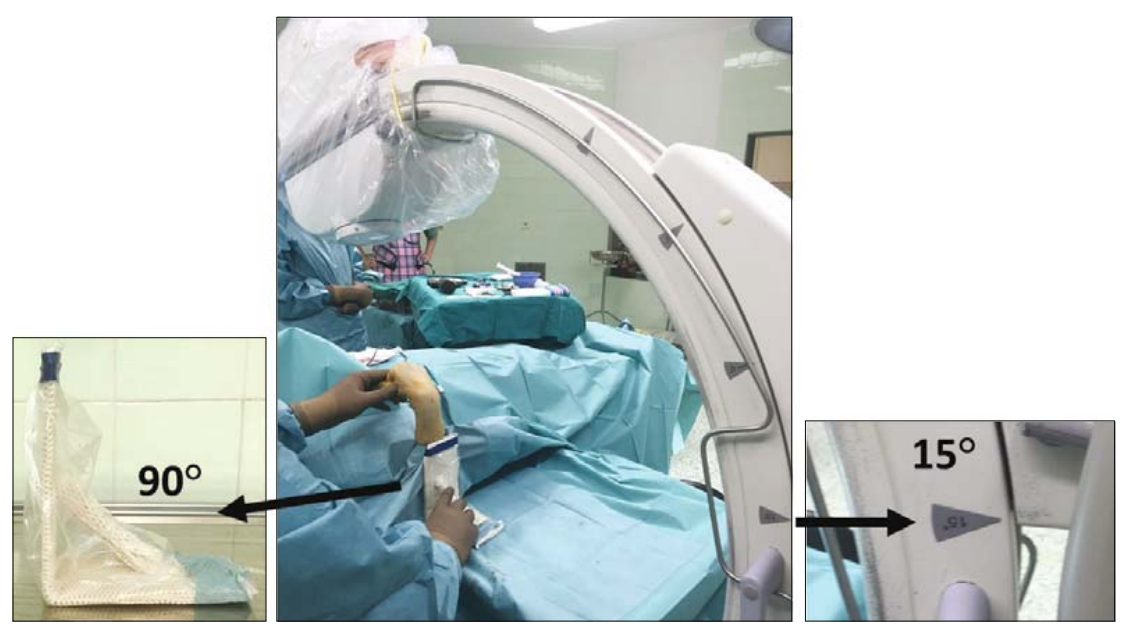

Fig. 2. Our modified DTV. The forearm was held at $90^{\circ}$ of flexion in elbow using a plastic template, the wrist in maximum flexion, and the $\mathrm{C}$-arm at $15^{\circ}$ inclination.

gists, each with a minimum of 10 years of experience. The operations were performed under a general anesthesia and tourniquet control.

The longitudinal Henry volar approach was used, and the radius was exposed. Anatomic fracture reduction was performed. The positioning of the plate was determined by placing a needle in the radio-carpal, another in the distal radioulnar joint, and by attaching the drill sleeve (Fig. 1). The distal end of the drill sleeve had a $5 \mathrm{~mm}$ gage and allowed optimal distal and ulnar positions of the volar plate to be set as described by Phillips and Al-Shawi (15). The correct position of the plate was also controlled with an image intensifier. A proximal cortex (non-locking) screw was inserted through the elongated combi hole to maintain plate posi- tion. The lengths of the distal screws were measured with a depth gage after drilling through the fixed-angle end of the VA-LCP drill sleeve. If a reliable measuring was impossible because of dorsal comminution, the screw lengths were estimated in lateral $\mathrm{X}$-ray views. Only distal row screws were inserted from the radial to the ulnar aspect (holes 1-4) (Fig. 1). The construct was then secured with a second proximal (locking) screw. The fracture reduction and screw positioning were checked by X-ray in the standard anteroposterior, lateral view and the lengths of the distal screws were finally checked in the DTV with the patient's arm placed on a radiolucent table.

Our modified DTV was performed at $15^{\circ}$ inclination of the $\mathrm{C}$-arm with the elbow in a right angle. The forearm was held in $90^{\circ}$ of flexion in elbow using a plastic template and the wrist in maximum flexion (Fig. 2). The ideal screw length in the DTV was when (i) the tip of the locking head screw was as close as possible to the DC but not less than $2 \mathrm{~mm}$ below the DC and (ii) the screw penetrated the DC no farther than $1 \mathrm{~mm}$, which should be clinically irrelevant $(7,16)$. The reference was $2 \mathrm{~mm}$ K-wire (Fig. 3). Screws out of limit were replaced by ones that were $2 \mathrm{~mm}$ shorter or longer, and a new DTV was taken; $2 \mathrm{~mm}$ is the minimum interval of the screws in the manufacturer's set. A postoperative CT (SOMATOM Sensation, Siemens) was then obtained to check and identify hardware out of limit. The screw lengths and any out of limit were measured by an orthopedic registrar who was blinded to the patient data. The screw lengths were measured in millimeters at $350 \%$ magnification using a TomoCon viewer (series 18.0.2540). Screws in four distal holes were measured from the radial to the ulnar side. We calculated the sensitivity of the DTV in detecting screws out of limit compared to CT scans (Fig. 4). Based on the CT scans, we estimated the ideal and safest screw lengths in the level of $2 \mathrm{nd}, 3 \mathrm{rd}$, and 4 th dorsal compartments.

Data were compared using the Fisher's exact test. Testing was performed at a significance level of $\alpha=0.05$. Statistical evaluation and interpretation of results was performed using the IBM SPSS Statistics 20 statistical program.

\section{Results}

In the one hundred distal screws, the mean $\pm \mathrm{SD}$ screw lengths at holes $1-4$ were $14.6 \pm 1.4 \mathrm{~mm}, 19.8 \pm 0.9 \mathrm{~mm}, 20.2 \pm 1.1 \mathrm{~mm}$, 


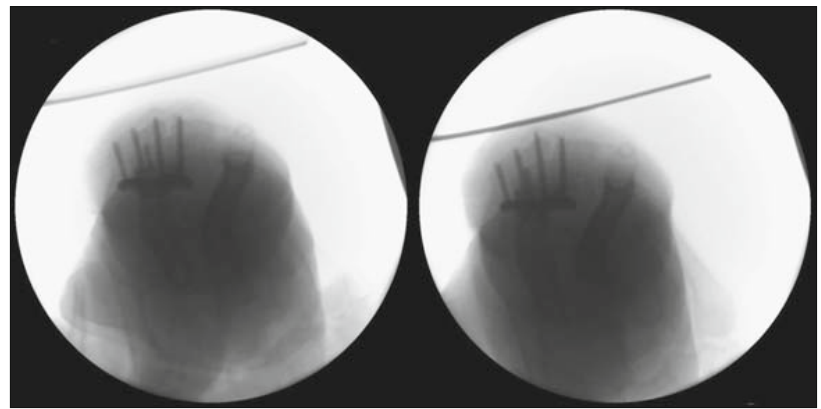

Fig. 3. During the DTV, $2 \mathrm{~mm}$ K-wire was used as a reference. In this created example, the $3^{\text {rd }}$ screw was changed for a longer one because the distance between the tip of the previous screw and the dorsal radial cortex was too small.

and $20.0 \pm 0.6 \mathrm{~mm}$, respectively. In intra-operative DTVs of the 25 female distal radius fractures, two of 100 distal locking screws were considered intra-operatively to be penetrating the DC by more than $1 \mathrm{~mm}$, and four of 100 appeared to be shorter than 2 $\mathrm{mm}$ (measured from the DC). Five screws in the first hole (second dorsal compartment) and one in the fourth hole (fourth dorsal compartment) were considered intra-operatively to be out of limit. Postoperative CT scans found six additional screws (6\%) perforating the $\mathrm{DC}$ by more than $1 \mathrm{~mm}$ (mean $0.65 \pm 0.91 \mathrm{~mm}$ ) and ten screws $(10 \%)$ that were more than $2 \mathrm{~mm}$ below the DC (mean $0.55 \pm 0.33 \mathrm{~mm}$ ). All screws changed intraoperatively were in the limit as measured by postoperative CT scans. Table 1 summarizes the total screw prominence $(>1 \mathrm{~mm})$ and shortness $(<2 \mathrm{~mm})$ in all four DPHs in the DTVs and CT scans. According to the CT scans, none of the screws had over-penetrated in the third dorsal compartment, over-penetration $(\mathrm{n}=6)$ was found in the second and fourth dorsal compartment (Tab. 2). The DTV was $88 \%, 84$ $\%, 88 \%$, and $76 \%$ sensitive in detecting screws within a limit in the first, second, third, and fourth DPHs, respectively.

The optimal screw lengths for the four DPHs in the optimally positioned locking plate are 14, 20, 20, and $20 \mathrm{~mm}$ in holes $1-4$,
Tab. 1. The number of prominent ( $>1 \mathrm{~mm}$ over dorsal cortex (DC)) and shorter ( $>2 \mathrm{~mm}$ below DC) screws in all four DPHs in the DTVs and CT scans.

\begin{tabular}{|c|c|c|c|c|}
\hline \multirow[b]{2}{*}{ Hole } & \multirow[b]{2}{*}{$\begin{array}{l}\text { Dorsal extensor } \\
\text { compartment }\end{array}$} & DTV & CT scan & \multirow[b]{2}{*}{ p-value } \\
\hline & & $\begin{array}{l}\text { Prominent screws } \\
(>1 \mathrm{~mm} \text { over DC) }\end{array}$ & $\begin{array}{l}\text { Prominent screws } \\
(>1 \text { mm over DC) }\end{array}$ & \\
\hline $1 \mathrm{st}$ & \multirow{2}{*}{2 nd } & 2 & 2 & \multirow{5}{*}{0.25} \\
\hline 2nd & & 0 & 1 & \\
\hline $3 \mathrm{rd}$ & $3 \mathrm{rd}$ & 0 & 0 & \\
\hline 4th & 4 th & 0 & 3 & \\
\hline Total & & 2 & 6 & \\
\hline
\end{tabular}

\begin{tabular}{|c|c|c|c|c|}
\hline \multirow[b]{2}{*}{ Hole } & \multirow[b]{2}{*}{$\begin{array}{l}\text { Dorsal extensor } \\
\text { compartment }\end{array}$} & DTV & CT scan & \multirow[b]{2}{*}{ p-value } \\
\hline & & $\begin{array}{c}\text { Shorter screws } \\
(>2 \mathrm{~mm} \text { below DC) }\end{array}$ & $\begin{array}{c}\text { Shorter screws } \\
(>2 \mathrm{~mm} \text { below DC) }\end{array}$ & \\
\hline 1 st & \multirow{2}{*}{2 nd } & 3 & 1 & \multirow{5}{*}{0.14} \\
\hline 2nd & & 0 & 3 & \\
\hline $3 \mathrm{rd}$ & $3 \mathrm{rd}$ & 0 & 3 & \\
\hline 4th & 4th & 1 & 3 & \\
\hline Total & & 4 & 10 & \\
\hline
\end{tabular}

Tab. 2. All over-penetrated screws (defined as screws penetrating $>1 \mathrm{~mm}$ over dorsal cortex (DC)) and all shorter screws (defined as screws $>2 \mathrm{~mm}$ below DC) measured by postoperative CT scans.

\begin{tabular}{|c|c|c|c|c|c|c|c|}
\hline \multirow{3}{*}{$\begin{array}{l}\text { Hole } \\
1 \mathrm{st} \\
\end{array}$} & \multirow{3}{*}{$\begin{array}{c}\text { Dorsal extensor } \\
\text { compartment }\end{array}$} & \multicolumn{6}{|c|}{ CT scan } \\
\hline & & \multicolumn{3}{|c|}{$\begin{array}{l}\text { Prominent screws } \\
\text { (>1 mm over DC) }\end{array}$} & \multicolumn{3}{|c|}{$\begin{array}{c}\text { Shorter screws } \\
(>2 \text { mm below DC) }\end{array}$} \\
\hline & & +0.13 & +0.5 & & -0.66 & & \\
\hline 2nd & & +0.4 & & & -1.06 & -0.82 & -0.26 \\
\hline $3 \mathrm{rd}$ & $3 \mathrm{rd}$ & & & & -0.5 & -0.3 & -0.19 \\
\hline 4th & 4th & +0.1 & +0.29 & +2.47 & -1.02 & -0.49 & -0.2 \\
\hline
\end{tabular}

respectively, from the radial to the ulnar aspect (Tab. 3). Using only $14 \mathrm{~mm}$ screws in the $1 \mathrm{st}$ hole would be sufficient in $76 \%$ of patients, but $12 \mathrm{~mm}$ screws would never penetrate the DC by more than $1 \mathrm{~mm}$. Using $20 \mathrm{~mm}$ screws in the 2 nd hole would be accurate in $68 \%$ of patients, but $18 \mathrm{~mm}$ screws would never penetrate the DC by more than $1 \mathrm{~mm}$. Using $20 \mathrm{~mm}$ screws in the 3rd hole, 76 $\%$ would be in the limit, but $18 \mathrm{~mm}$ screws would never penetrate the DC. The most-proper screw length in the 4th hole is $20 \mathrm{~mm} \mathrm{(72 \%} \mathrm{ac-}$ curate), but $18 \mathrm{~mm}$ screws would penetrate $4 \%$ of dorsal cortices.

The average follow-up was 15.3 \pm 7.9 (5-37) months. One patient presented with pain and swelling of the carpus; the pain was located over the fourth dorsal compartment. Surgery confirmed extensor tendons lession.

\section{Discussion}

Using screws that are too long in the volar plating of a distal radius

Fig. 4. Four distal screws in DTV compared to CT scan. 
Tab. 3. The optimal screw lengths for the four DPHs in the optimally positioned locking plate and the calculation of the safest screw lengths to ensure maximum safety from over-penetration.

\begin{tabular}{lcccc}
\hline \multirow{4}{*}{ Hole } & \multicolumn{4}{c}{ Screw n (\%) } \\
\cline { 2 - 5 } & $\begin{array}{c}\text { length } \\
(\mathrm{mm})\end{array}$ & $\begin{array}{c}\text { penetrate } \\
>1 \text { mm over DC }\end{array}$ & $\begin{array}{c}\text { shorter } \\
\text { mm below DC }\end{array}$ & in limit \\
\hline \multirow{4}{*}{ 1st } & 12 & 0 & $15(60)$ & $10(40)$ \\
& 14 & $3(12)$ & $3(12)$ & $19(76)$ \\
& 16 & $12(48)$ & 0 & $13(52)$ \\
& 18 & $22(88)$ & 0 & $3(12)$ \\
\hline \multirow{4}{*}{2 nd } & 18 & 0 & $12(48)$ & $13(52)$ \\
& 20 & $5(20)$ & $3(16)$ & $17(68)$ \\
& 22 & $17(68)$ & 0 & $8(32)$ \\
3 & 18 & 0 & $19(76)$ & $6(24)$ \\
& 20 & $1(4)$ & $5(20)$ & $19(76)$ \\
& 22 & $6(44)$ & $8(4)$ & $11(52)$ \\
\hline \multirow{4}{*}{ 4th } & 18 & $1(4)$ & $13(52)$ & $11(44)$ \\
& 20 & $4(16)$ & $3(12)$ & $18(72)$ \\
& 22 & $18(72)$ & 0 & $7(28)$ \\
\hline
\end{tabular}

DC - dorsal cortex

fracture can violate the dorsal extensor compartments and can cause irritation and rupture of the extensor pollicis longus tendon $(5-7,17)$ Also, irritations of other dorsal tendons and their compartments are no exception $(6,7,16,18)$. Intraoperatively, assessing all screw prominences in a distal radius fracture by multiple views is challenging because of the complex geometry of the distal radial bone $(19,20)$. The DTV, also called the dorsal horizon, skyline, or Dönicke view has been described as a useful tool for visualizing the radial DC and its relationship to the screw tips $(9,12,21,22)$.

There are two described techniques to achieve DTV. The first (and mostly used) is with the supinated forearm inclined at $15^{\circ}$ to the vertical $\mathrm{X}$-ray beam with maximum wrist flexion $(8,12,13,21,23-26)$. The second is with a pronated forearm and horizontally placed fluoroscope with the X-ray beam parallel to the dorsal aspect of the distal radius $(9,27)$. In our study, we present the third technique, with a supinated forearm with the elbow at $90^{\circ}$, the wrist in maximal flexion, and the fluoroscope inclined at $15^{\circ}$ to the X-ray beam. We found this third approach very practical, it being easier to determine and keep the right angle in the elbow than a $15^{\circ}$ angle of forearm inclination. It has been recommended to use a sterile goniometer to measure forearm tilt radius (21), whereas in our technique one can use anything sterile with a right angle. The only requirement is to have an adjustable $\mathrm{C}$-arm.

During the volar plating, screws that are too long could harm the extensor tendons, whereas shorter ones could compromise the stability, especially when the dorsal-ulnar fragment is present $(5,6,9,11,12-14,16)$. According to the literature, screw penetration greater than $1.0 \mathrm{~mm}$ is likely to cause problems $(7,16)$. Therefore, some authors have proposed that distal screws should be routinely 2-4 mm shorter than measured $(5,10,23,28,29)$ and that a screw length of $75 \%$ of the distal radius bone offers fixation that is as strong as a bicortical construct (30). However, the comminution of the DC usually prevents an adequate drilling through opposite cortex and accurate depth-gauge measurement, and calculating $75 \%$ of an unknown screw measurement is quite tricky. In that situation, inserting the most-suitable distal locking screw for each hole and then applying the DTV seems to be a simpler and safer option. In our study, we tried to calculate the DTV sensitivity and the optimal screw lengths in four distal locking holes with a screw trajectory at $15^{\circ}$ angulation. We used only four distal screws, which is biomechanically sufficient to preserve the stability of the fracture $(25,31)$.

Screw exchange during surgery after a skyline view varies from $5.17 \%$ to $26.6 \%(8,13,23,25,32,33)$. In a study by Rausch et al, 12 of 232 screws $(5.17 \%)$ were exchanged after obtaining a DTV (13). In a clinical study by Ganesh et al, nine prominent screws of $10(5.71 \%)$ revealed by the DTV were exchanged (23). In the series of 25 consecutive patients, dorsal over-penetration of screws was discovered in two cases ( $8 \%$ ) (32). Brunner et al changed 11 screws of $93(11.82 \%)$ during surgery (33), and in the study by Vaiss et al it was $14.66 \%$ (11 of 75 patients) (8). In the study by Joseph and Harvey, using the skyline view led to a change in screw length in $26.6 \%$ of cases (4 of 15 patients) (25). In our study, we changed six (6\%) screws: two (2\%) were rated as too long and four (4\%) as too short. Postoperative CT scans revealed another $16(16 \%)$ screws as screws out of limit, of which six ( $6 \%)$ were prominent, and $10(10 \%)$ were too short.

The DTV was sensitive at detecting screw penetration into the $3^{\text {rd }}$ and $4^{\text {th }}$ compartments with a sensitivity of $88 \%$ for $1 \mathrm{~mm}$ of penetration, whereas for screws in the $2^{\text {nd }}$ dorsal compartment it was only $35 \%$ in detecting a screw prominence of $1 \mathrm{~mm}$ (22). In the study by Brunner et al, screws in the 3rd and 5th screw holes (3rd and 4th dorsal compartments) showed the highest correlation between DTV and CT, whereas the screws in the 1st hole (2nd dorsal compartment) showed the lowest correlation (33). In the study by Ganesh et al, the DTV sensitivity was $100 \%$ in detecting prominent screws in the 3rd dorsal compartment, whereas it was only $50 \%$ in the 4 th dorsal compartment and $60 \%$ in the 2 nd (23). In the study using a sawbones model, the skyline view was $83 \%$ sensitive for detecting dorsal cortical penetration by $1 \mathrm{~mm}$ (24). In our study, the lowest sensitivity was found for the 4th hole and caused tenosynovitis in one case, which required a surgical revision. The majority of authors recommend using oblique views to evaluate the 2 nd and 4 th compartments, and we agree with that.

There are several limitations to the present study. Only female patients were evaluated; however, this selection was made intentionally considering that females are more affected than males. We used only one type of volar plate; however, the plate used in the study is commonly used worldwide. Another limitation is that we did not measure the exact length of a screw's under- or overpenetration through the DC during the DTV, and so we cannot report the values accurately in millimeters. Hoverer, $2 \mathrm{~mm} \mathrm{~K}$-wire served as a good reference and this could be done quickly during the operation to reach a limit. The screws were changed according to the decision of the operating surgeon, and so the specificity of the DTV could not be assessed.

\section{Conclusion}

Using a $2.4 \mathrm{~mm}$ locking compression plate or a similar volar locking plate with a screw trajectory at $15^{\circ}$ angulation, the most-accurate screw lengths in the four most DPHs are 14, 20,20, and $20 \mathrm{~mm}$ 
from the radial to the ulnar aspect in distal radius fractures in female patients. By our calculation, using 12, 18, 18, and $18 \mathrm{~mm}$ screws from the radial to the ulnar aspect should ensure the maximum safety from over-penetration. In DC comminution, in a situation when perioperative measuring is imprecise, inserting the most-suitable distal locking screw for problematic hole and then applying our modified DTV seems to be a more straightforward and safer option.

\section{References}

1. Jerrhag D, Englund M, Karlsson MK, Rosengren BE. Epidemiology and time trends of distal forearm fractures in adults - a study of 11.2 million person-years in Sweden. BMC Musculoskelet Disord 2017; 18 (1): 240.

2. Gajdoš R, Božík M, Straňák P. Is an implant removal after dorsal plating of distal radius fracture always needed? Bratisl Med J 2015; 116 (6): 357-362.

3. Clement ND, Duckworth AD, Wickramasinghe NR, Court-Brown CM, MM. Does socioeconomic status influence the epidemiology and outcome of distal radial fractures in adults? Eur J Orthop Surg Traumatol 2017; 27 (8): 1075-1082.

4. Rozental TD, Blazar PE. Functional outcome and complications after volar plating for dorsally displaced, unstable fractures of the distal radius. J Hand Surg Am 2006; 31: 359-365.

5. Arora R, Lutz M, Hennerbichler A, Krappinger D, Espen D, Gabl M. Complications following internal fixation of unstable distal radius fracture with a palmar locking plate. J Orthop Trauma 2007; 21: 316-322.

6. Al-Rashid M, Theivendran K, Craigen MA. Delayed ruptures of the extensor tendon secondary to the use of volar locking compression plates for distal radial fractures. J Bone Joint Surg Br 2006; 88: 1610-1612.

7. Bianchi S, van Aaken J, Glauser T, Martinoli C, Beaulieu JY, Della Santa D. Screw impingement on the extensor tendons in distal radius fractures treated by volar plating: Sonographic apperance. AJR 2008; 191 : 199-203.

8. Vaiss L, Ichihara S, Hendriks S, Taleb C, Liverneaux P, Facca S. The utility of the fluoroscopic skyline view during volar locking plate fixation of distal radius rractures. J Wrist Surg 2014; 3: 245-249.

9. Ozer K, Toker S. Dorsal tangential view of the wrist to detect screw penetration to the dorsal cortex of the distal radius after volar fixed-angle plating. Hand (N Y) 2011; 6: 190-193.

10. Musgrave DS, Idler RS. Volar fixation of dorsally displaced distal radius fractures using the 2.4-mm locking compression plates. J Hand Surg Am 2005; 30: 743-749.

11. Melone CP. Open treatment for displaced articular fractures of the distal radius. Clin Orthop Relat Res 1986; 202: 103-111.

12. Giugale JM, Fourman MS, Bielicka DL, Fowler JR. Comparing dorsal tangential and lateral views of the wrist for detecting dorsal screw penetration after volar plating of distal radius fractures. Advances in Orthopedics 2017; 2017: 1-5.

13. Rausch S, Marintschev I, Graul I, Wilharm A, Klos K, Hofmann GO, Gras MF. Tangential view and intraoperative three-dimensional fluoroscopy for the detection of screw-misplacament in volar plating of distal radius fractures. Arch Trauma Res 2015; 4 (2): 1-5.

14. Austin A, Green S, Ahsan S, Roskosky M, Shuler MS. Cadaveric study of appropriate screw lenght for distal radius stabilitation using volar plate fixation. Am J Orthop (Belle Mead NJ) 2015; 44 (8): 369-372.

15. Phillips AR, Al-Shawi A. Optimal positioning of the DVR plate in distal radius fractures: A cadaveric examination of a referencing technique. Injury, Int. J. Care Injured 2012; 43: 209-212.
16. Sügün TS, Karabay N, Gürbüz Y, Ozaksar K, Toros T, Kayalar M. Screw prominences related to palmar locking plating of distal radius. J Hand Surg Eur Vol 2011; 36 (4): 320-324.

17. Skoff HD. Postfracture extensor pollicis longus tenosynovitis and tendon rupture: a scientific study and personel series. Am J Orthop 2003; 32: 245-247.

18. Maschke SD, Evans PJ, Schub D, Drake R, Lawton JN. Radiographic evaluation of dorsal screw penetration after volar fixed-angle plating of the distal radius: a cadaveric study. Hand 2007; 2: 144-150.

19. Pichler W, Windisch G, Schaffler G, Reinmüller R, Grechenig W. Computer tomography aided 3D analysis of the distal dorsal radius surface and the effect on volar plate osteosynthesis. The journal of hand surgery 2009; 34E5: 598-602.

20. Clement H, Pichler W, Nelson D, Hausleitner L, Tesch PN, Grechenig W. Morphometric analysis of Lister s tubercle and its consequenses on volar plate fixation of distal radius fracture. J Hand Surg 2008; 33A: 1716-1719.

21. Haug LC, Glondy B, Deml C, Lutz M, Attal R. A new radiological method to detect dorsally penetrating screws when using volar locking plates in distal radial fractures. The dorsal horizon view. Bone Joint J 2013; 95-B: 1101-1105.

22. Ozer K, Wolf JM, Watkins B, Hak DJ. Comparison of 4 fluoroscopic views for dorsal cortex screw penetration after volar plating of the distal radius. J Hand Surg 2012; 37A: 963-967.

23. Ganesh D, Service B, Zirgibel B, Koval K. The detection of prominent hardware in volar locked plating of distal radius fractures: intraoperative fluoroscopy versus computed tomography. J Orthop Trauma 2016; 30: 618-621.

24. Riddick AP, Hickey B, White SP. Accuracy of the skyline view for detecting dorsal cortical penetration during volar distal radius fixation. J Hand Surg Eur Vol 2012; 37: 407-411.

25. Joseph SJ, Harvey JN. The dorsal horizon view: detecting screw protrusion at the distal radius. J Hand Surg 2011; 36A: 1691-1693.

26. Gurbuz Y, Kucuk L, Gunay K, Ozaksar K, Sugun TS. Comparison of ultrasound and dorsal horizon radiographic view for the detection of dorsal screw penetration. Acta Orthop Traumatol Turc 2017; 51 (6): 448-450.

27. Hill BW, Shakir I, Cannada LM. Dorsal screw penetration with the use of volar plating of distal radius fractures: how can you best detect? J Orthop Trauma 2015; 29: 408-413.

28. Benson EC, DeCarvalho A, Mikola EA, Veitch JM, Moniem MS. Two potential causes of EPL rupture after distal radius volar plate fixation. Clin Orthop Relat R 2006; 451: 218-222.

29. Yuen G, Yee DK, Fang C, Lau TW, Leung F. Screw length in volar locking plate fixation for distal radial fractures. J orthop Surg 2015; 23 (2): 164-167.

30. Wall LB, Brodt MD, Silva MJ, Boyer MI, Calfee RP. The effects of screw length on stability of simulated osteoporotic distal radius fractures fixed with volar locking plates. Journal of Hand Surgery 2012; 37: 446-453.

31. Moss DP, Means KR, Parks BG. A biomechanical comparison of volar locked plating of intra-articular distal radius fractures: use of 4 versus 7 screws for distal fixation. J hand Surg Am 2011; 36: 1907-1911.

32. Taylor BC, Malarkey AR, Eschbaugh RL, Gentile J. Distal radius skyline view: how to prevent dorsal cortical penetration. J Surg Orthop Adv 2017; 26 (3): 183-186.

33. Brunner A, Siebert C, Stieger C, Kastius A, Link BC, Babst R. The dorsal tangential X-ray view to determine dorsal screw penetration during volar plating of distal radius fractures. J hand Surg Am 2015; 40 (1): 27-33. 